\title{
Solar Permeability of Different Tree Species in Szeged, Hungary
}

\author{
Ágnes Takács ${ }^{\mathrm{A}}$, Márton Kiss ${ }^{\mathrm{A}}$, Ágnes Gulyás ${ }^{\mathrm{A}}$, Eszter Tanács ${ }^{\mathrm{A}}$, Noémi Kántor ${ }^{\mathrm{A}}$ \\ Received: October 11, 2015 | Revised: January 25, 2016 | Accepted: March 15, 2016
}

\begin{abstract}
The heat stress modification capacity of urban trees is widely acknowledged and makes these natural landscape elements very important in the field of climate conscious urban planning. Many studies proved that shading, i.e. the reduction of direct solar radiation is the most effective way to moderate summer heat stress under Central European climatic conditions. The investigation aims at determining the transmissivity of four tree species that occur frequently in Hungarian cities: Sophora japonica, Tilia cordata, Celtis occidentalis and Aesculus hippocastanum. In order to accomplish that, a systematic radiation measurement campaign was carried out in the South-Hungarian city of Szeged, from early summer (foliated condition of trees) to late autumn (nearly leafless condition). Short-wave radiation from the upper hemisphere was measured with Kipp \& Zonen pyranometers under carefully selected tree specimens (transmitted radiation), as well as on a roof station free from sky obstruction (actual value of global radiation). The calculated transmissivity values varied greatly with the seasonal status of the canopy (the median value of transmissivity increased from 0.03 to 0.47 in case of A. hippocastanum), and we found considerable inter-species differences too, evidencing that solar permeability depends on the amount of leaves, leaf density and other tree crown-related characteristics.
\end{abstract}

Key words: shading potential, transmissivity, urban trees, Szeged, Hungary

\section{Introduction}

Urban adaptation strategies become ever more important, considering the rapid growth in urban population as well as the predicted effects of climate change (UNFPA, 2011; IPCC, 2014). According to the latest research results, summer heat stress will increase more in cities than in rural and natural areas (Pochter, BenShalom, 2013; Zuvela-Aloise, et al., 2015). More severe and longer-lasting heat stress periods are expected, which means even greater challenge for city dwellers. Several earlier studies have demonstrated that many urban design-related microclimates result in significant level of bioclimatic stress in certain periods, especially in summer. Under Central-European climate conditions, extreme heat stress at the street level is usually the effect of high solar radiation and the resulting high radiation budget of pedestrians (eg. Gu- lyás, Unger, 2010; Kántor, Unger, 2011; Égerházi, et al., 2013; Lee, et al., 2014). Carefully designed shading is therefore essential in the fight against heat stress and in the creation of comfortable outdoor places (Lee, et al., 2013). The most obvious way of shadowing, which incidentally also offers the most additional services in urban ecosystems, is the usage of vegetation, especially shade trees (Carver, et al., 2004; Shashua-Bar, et al., 2009; Shadidan, et al., 2010).

The heat stress mitigating nature of urban trees is widely acknowledged and makes these natural landscape elements very important in the field of climateconscious urban planning (Shashua-Bar, Hoffmann, 200o; Bowler, et al., 2010; Erell, et al., 2011; Shashua-Bar, et al., 2011). Many studies based on micrometeorological measurements and/or model simulations have proved that shading, i.e. the reduction of direct solar radiation is the most effective way to moderate summer heat stress

\footnotetext{
A Department of Climatology and Landscape Ecology, University of Szeged, 2 Egyetem Street, 6722 Szeged, Hungary

* Corresponding author: Ágnes Takács, e-mail: takacsagi@geo.u-szeged.hu
} 
under Central-European climate conditions (e.g. Mayer, 2008; Mayer, et al., 2008; Égerházi, et al., 2013,2014; Kántor, et al., 2016). Shade trees have positive effect not only on outdoor thermal comfort, but also on thermal conditions inside buildings (Akbari, et al., 1997; Donovan, Butry, 2009). The shadowing of exposed walls, especially west- or south-facing ones (in Central-Europe), lessens the warming of interiors. In a hot climate, trees planted around buildings (when applying the right species to the right place) positively influence the energy balance and reduce the energy requirements of cooling them through sheltering the windows, walls, and rooftops from strong direct solar radiation and from the radiation reflected from the surroundings (Nakaohkubo, Hoyano, 2011; Berry, et al., 2013).

The shading potential of trees is usually described by their transmissivity values (or solar permeability), i.e. by the proportion of solar radiation transmitted through their foliage (Cantón, et al., 1994; Konarska, et al., 2014). Despite the importance of the thermal stress reducing effect of shade trees, the number of relevant studies with practical outcomes is very small, and there is a lack of information about the speciesspecific shading and bioclimate-regulation capacity of trees. In order to help fill in the knowledge gap we aim to determine the transmissivity differences among common urban trees that occur frequently in Central-European climate conditions, and analyze the intra-annual changes in transmissivity as well. Our long-term objective is to provide a reliable picture of the radiation-modification effect of urban trees. In order to accomplish this, a systematic series of measurements were carried out in the city of Szeged (SE Hungary), on common urban tree species, which covered the whole vegetation period.

This study aims to present the main findings and experiences from the first year of these long-term transmissivity measurements (2014) focusing mainly on

- the temporal change in transmissivity induced by autumn defoliation,

- and the inter-species differences.

These results can be used in microclimate simulation software to enable more reliable modeling, and thus provide help for urban designers and landscape architects in selecting the appropriate shade tree species.

\section{Methods and data}

Szeged is situated in the south-eastern part of Hungary $\left(46^{\circ} \mathrm{N}, 20^{\circ} \mathrm{E} ; 82 \mathrm{~m}\right.$ above sea level), with a population of about 162 ooo. This region of Hungary can be characterized with dry-warm continental climate, with significant drought susceptibility at summer. Based on data from the Hungarian Meteorological Service, the total annual sunshine is 2023 hours; the

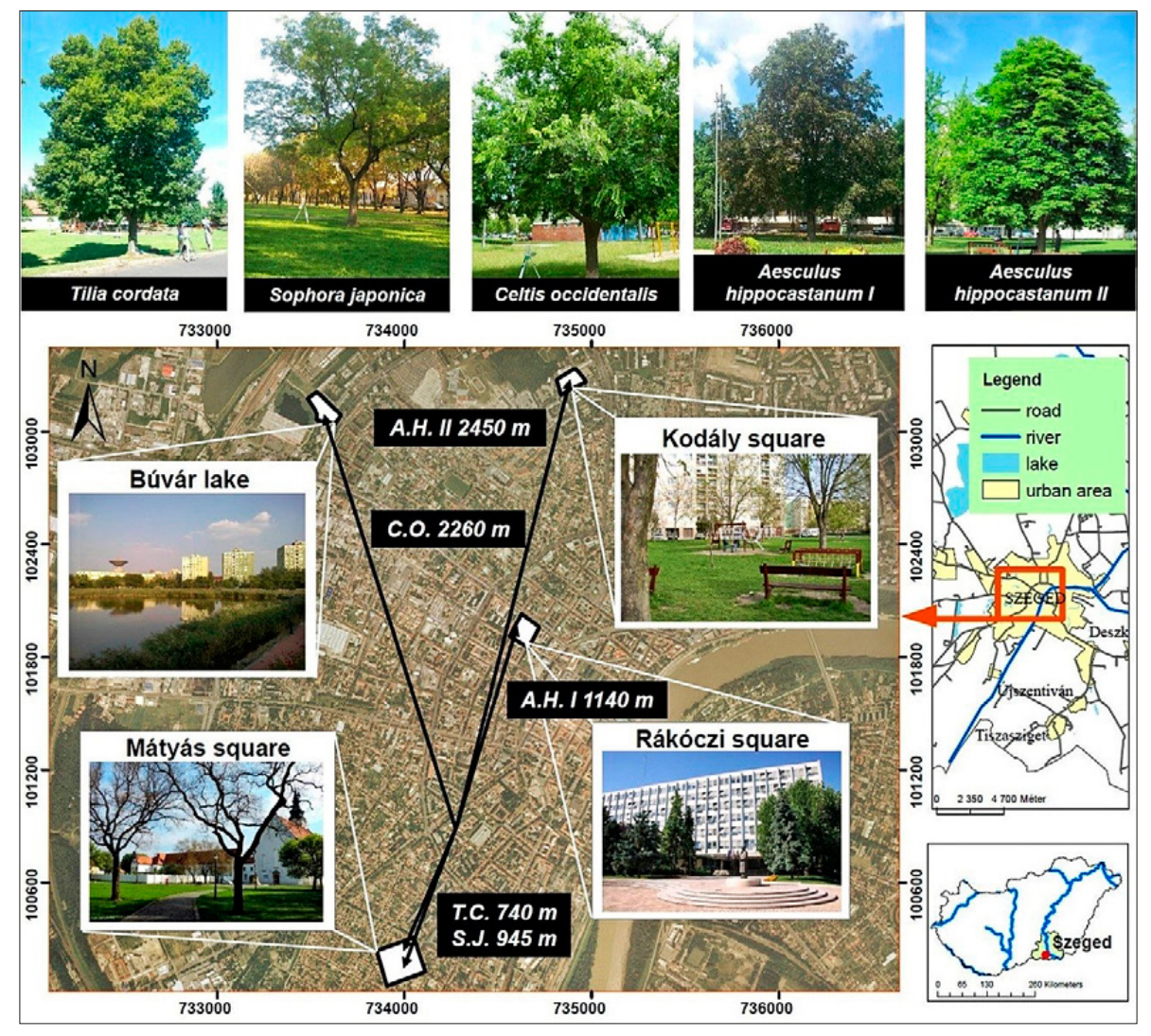

Figure 1. The examined tree specimens and study areas in Szeged, Southeast Hungary 
mean annual temperature is $10.5^{\circ} \mathrm{C}$, while the annual sum of precipitation is only $495 \mathrm{~mm}$ (WMO, 1996). The street network of the city forms a circuit-avenue system, and there are several different land-use types from the densely built-up inner city to the detached housing suburban region. The study areas for this investigation are recreational places (at the Búvár lake, Kodály sq., Mátyás sq., and Rákóczi sq.) in the urbanized region of Szeged (Figure 1).

A systematic measurement series was organized in order to analyze the intra-annual changes of transmissivity of four tree species frequently planted in Hungarian towns as street trees or park trees. The species are:

- Tilia cordata (small-leaved linden)

- Sophora japonica (pagoda tree)

- Celtis occidentalis (common hackberry)

- Aesculus hippocastanum (horse-chestnut).

To calculate the species-dependent transmissivity values, we measured the global radiation (total shortwave radiation from the upper hemisphere; sum of direct and diffuse solar radiation) at two locations:

- $G_{\text {trans }}\left[\mathrm{W} / \mathrm{m}^{2}\right]$ is the transmitted solar radiation measured in the shade of the selected urban tree,

- $G_{a c t}\left[\mathrm{~W} / \mathrm{m}^{2}\right]$ is the actual value of global radiation measured in a reference station (inner-city weather station) free from sky obstruction.

Transmissivity is then calculated as the ratio of these values $\left(G_{\text {trans }} / G_{a c t}\right)$.

In order to select the ideal tree specimens and locations for the investigations more field trips were conducted before the actual radiation measurements. The main criteria were to find healthy and adult individuals in the case of all investigated species without the disturbing effect of other natural or artificial landscape elements, i.e. to ensure that other objects do not influence the recorded parameters significantly during the measurement period (typically from 10 am to $4 \mathrm{pm}$ ). Suitable T. cordata and S. japonica individuals were found in Mátyás square within $1 \mathrm{~km}$ distance from the reference station (Table 1). The selected C. occidentalis tree stands by the Búvár-lake at a distance of over $2 \mathrm{~km}$, while the
A. hippocastanum specimen is in Rákóczi square within almost $1.1 \mathrm{~km}$. However, during the first summer period this specific tree was attacked by Cameraria ohridella (horse-chestnut leaf miner), resulting in earlier defoliation. In order to ensure continuous measurements a new, healthy A. hippocastanum individual was selected in Kodály square at a distance of almost $2.5 \mathrm{~km}$ (Table 1).

Two micrometeorological stations, equipped with Kipp \& Zonen net radiometers (CNR1 and $\mathrm{CNR}_{4}$ ), were used to record $G_{\text {trans }}$ values under the selected trees. The comparability of the two pyranometers of these net radiometers was tested on a cloudy and a totally clear summer day, and the average differences between the measured $G$ values were only 10.14 and $3.8 \mathrm{~W} / \mathrm{m}^{2}$ on the 2 days, respectively. All data considered, the differences ranged from -35 to $50 \mathrm{~W} / \mathrm{m}^{2}$ and did not exceed $25 \mathrm{~W} / \mathrm{m}^{2}$ in absolute value in more than $80 \%$ of the cases. During the measurement series the sensors were placed at a distance of $2 \mathrm{~m}$ on the northern side of the tree trunks, with special care concerning the right orientation, height and leveling. Pyranometers were situated at $1.1 \mathrm{~m}$ above ground level which corresponds to the gravity center of an adult European man, the usually applied standard subject in outdoor thermal comfort investigations (Mayer, 2008; Mayer, et al., 2008).

The reference Kipp \& Zonen pyranometer, measuring the $G_{a c t}$ values necessary for the transmissivity calculations, is located on the top of the four-storey building of the University of Szeged. It is run by the Hungarian Meteorological Service and records 10-minute mean values of global radiation. In order to be consistent with this temporal resolution, the $G_{\text {trans }}$ values measured with 1-minute resolution were also averaged.

In 2014 the field campaign lasted from June (foliated condition of trees) to November (nearly leafless condition) to determine not only the interspecies differences, but also the intra-annual changes of transmissivity induced by the autumn defoliation (Table 2). After the first four days, parallel measurements under the canopies of two different tree species were carried out at the same time allowing the comparison of their solar permeability under completely identical meteorological background conditions.

Table 1. Main dimensional attributes of the investigated urban trees

\begin{tabular}{|l|c|c|c|c|c|}
\hline Species & Tilia cordata & Sophora japonica & $\begin{array}{c}\text { Celtis } \\
\text { occidentalis }\end{array}$ & $\begin{array}{c}\text { Aesculus } \\
\text { hippocastanum I }\end{array}$ & $\begin{array}{c}\text { Aesculus } \\
\text { hippocastanum II }\end{array}$ \\
\hline $\begin{array}{l}\text { Distance from roof- } \\
\text { pyranometer [m] }\end{array}$ & 740 & 945 & 2260 & 1140 & 2450 \\
\hline Full height [m] & 15.5 & 12 & 9 & 15 & 13.5 \\
\hline Trunk height [m] & 2.5 & 3 & 1.8 & 2 & 2.5 \\
\hline Canopy diameter [m] & 9 & 12 & 14 & 10 & 9 \\
\hline Trunk diameter $[\mathrm{cm}]$ & 70.5 & 75 & 70 & 78 & 57 \\
\hline
\end{tabular}


Table 2. Measurement days and intervals in 2014 (colored days were selected for the analyses)

\begin{tabular}{|c|c|c|c|c|c|}
\hline Date & Sky conditions & Tilia cordata & Sophora japonica & Celtis occidentalis & $\begin{array}{c}\text { Aesculus } \\
\text { hippocastanum }\end{array}$ \\
\hline 27 / Jun /2014 & cloudy & & $10: 10-17: 20$ & & \\
\hline $1 /$ Jul / 2014 & overcast & $10: 10-17: 30$ & & & \\
\hline 2 / Jul / 2014 & cloudy & & & $9: 50-18: 10$ & \\
\hline 4 / Jul / 2014 & clear & & & & $10: 10-17: 40$ \\
\hline 24 / Jul / 2014 & cloudy & & & $9: 40-18: 10$ & $10: 10-16: 50$ \\
\hline 25 / Jul / 2014 & cloudy & $9: 40-17: 50$ & $10: 00-17: 40$ & & \\
\hline 28 / Aug / 2014 & cloudy & $10: 00-16: 50$ & $10: 20-16: 30$ & & \\
\hline 9 / Sep / 2014 & mostly clear & & & $9: 50-17: 20$ & $10: 10-17: 00$ \\
\hline 18 / Sep / 2014 & mostly clear & $10: 00-16: 30$ & $10: 20-16: 10$ & & \\
\hline 29 / Sep / 2014 & clear & $10: 00-16: 30$ & $10: 20-16: 10$ & & \\
\hline 30 / Sep / 2014 & clear & & & $9: 40-16: 40$ & $10: 00$ - 16:20 \\
\hline 28 / Oct / 2014 & clear & & & $10: 10-15: 00$ & $10: 40-14: 50$ \\
\hline 4 / Nov / 2014 & clear & $10: 00-14: 50$ & $10: 20-14: 30$ & & \\
\hline
\end{tabular}

\section{Results}

\section{Seasonal change of the foliage}

As clear sky conditions occurred most frequently in the case of A. hippocastanum, the effect of foliation status on solar permeability is presented on the example of this species. Figure 2 illustrates the daily curves of global radiation, transmitted radiation as well as
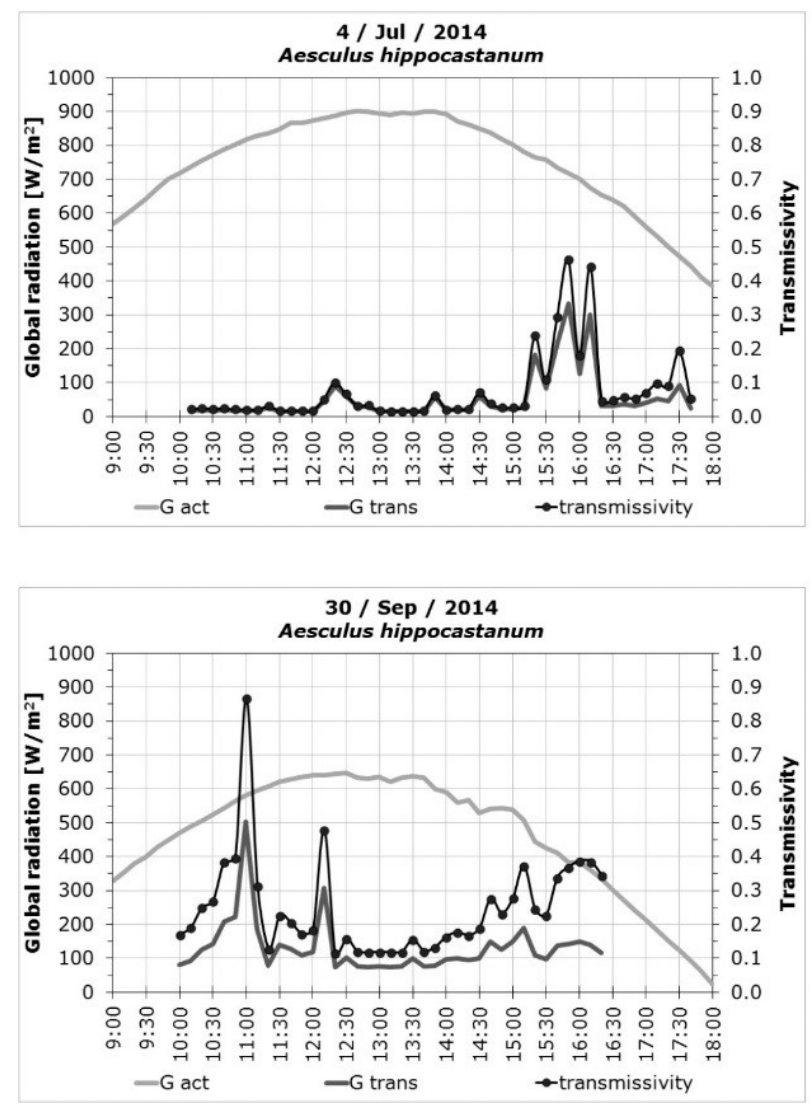

the calculated values of transmissivity on four clear days.

The daily maximum of $G_{a c t}$ was approx. 900 W/ $\mathrm{m}^{2}$ on 4 / Jul / 2014, while it reached only $500 \mathrm{~W} / \mathrm{m}^{2}$ on the last measurement day (28 / Oct / 2014) (Figure 2). The autumn defoliation effect is clearly shown: although $G_{a c t}$ decreased from midsummer to late autumn, $G_{\text {trans }}$ and consequently the transmissivity val-
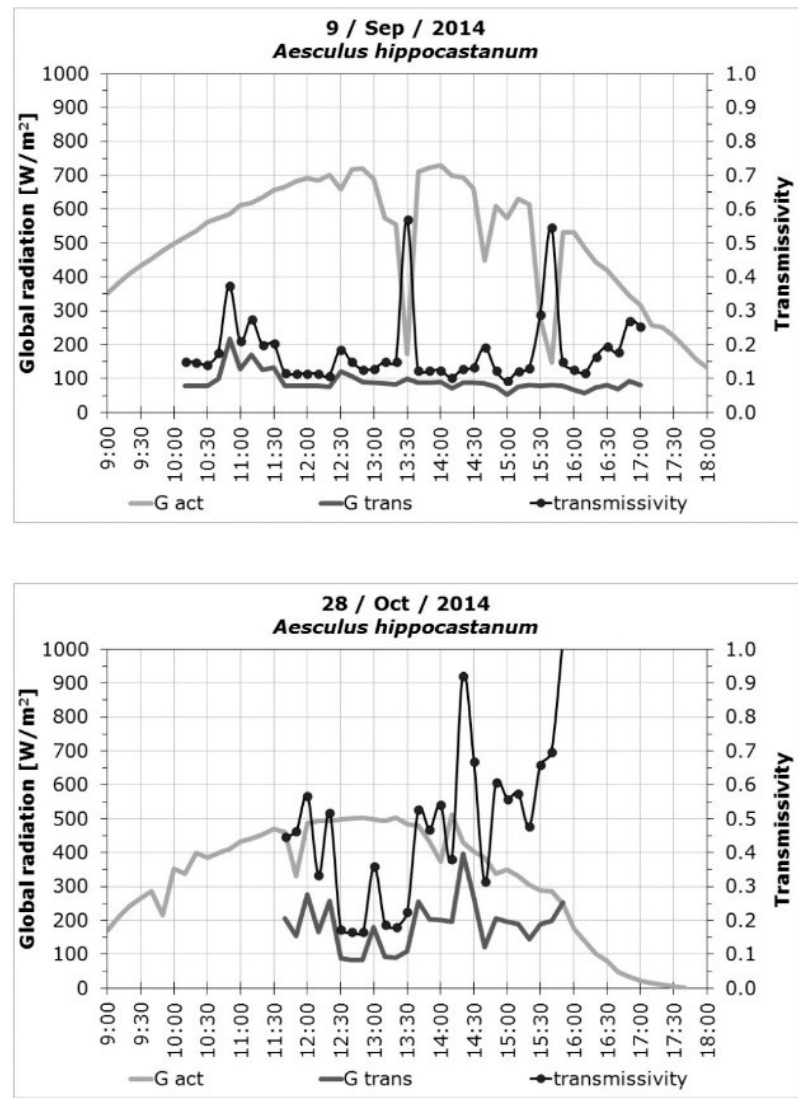

Figure 2. Seasonal change of solar permeability through the foliage of $A$. hippocastanum (time is in CET, $\mathrm{G}_{\text {act }}-\mathrm{actual}$ value of global radiation, $\mathrm{G}_{\text {trans }}$ - transmitted radiation) 


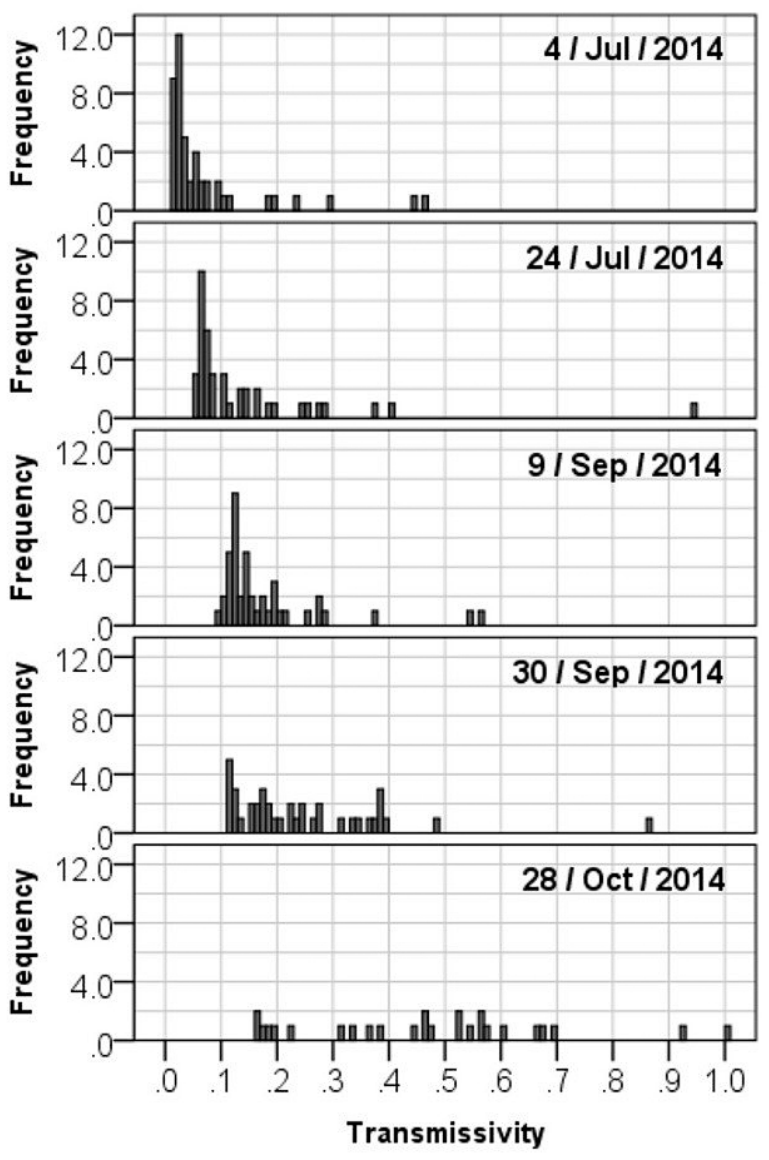

Figure 3. Transmissivity values of the Aesculus hippocastanum on different measurement days

ues as well increased continuously in the same period. $G_{\text {trans }}$ remained under $25 \mathrm{~W} / \mathrm{m}^{2}$ during almost the whole measurement interval on the first day, and had only a slight peak around 12:20 (CET - Central European Time). More remarkable increases (up to 200$300 \mathrm{~W} / \mathrm{m}^{2}$ ) occurred between 15:20 and 16:10 indicating that the point where we placed the mobile station got more insolation. The transmissivity values for the fully shaded interval ranged between 0.02 and 0.1 and increased above 0.4 only in the mentioned afternoon period with the chance of more direct irradiation. On 9 / Sep / $2014 G_{\text {trans }}$ was continuously around $100 \mathrm{~W} / \mathrm{m}^{2}$, except the short period from 10:50 to 11:30. The most common $G_{\text {trans }}$ values ranged between 100-200 W/ $/ \mathrm{m}^{2}$ on the last day of September, and the peaks were more pronounced: $500 \mathrm{~W} / \mathrm{m}^{2}$ and $300 \mathrm{~W} / \mathrm{m}^{2}$ around $11: 00$ and 12:00, respectively. The last day can be characterized with the highest $G_{\text {trans }}$ values scattering around $200 \mathrm{~W} / \mathrm{m}^{2}$, peaking at about $400 \mathrm{~W} / \mathrm{m}^{2}$ (Figure 2).

In conjunction with the decreasing $G_{a c t}$ and increasing $G_{\text {trans }}$ values during the summer-autumn interval, the transmissivity of A. hippocastanum continuously increased because of the autumn defoliation (Table 3, Figure 3). Since the arithmetic mean values are very sensitive to the extremes, we consider it more appropriate to characterize the frequency distribution of transmissivity with the median and mode. Half of the calculated transmissivity values were below 0.03 on the midsummer measurement day, while the medians were $0.08,0.15,0.21$ and 0.47 on the subsequent measurement days. The corresponding mode values were almost the same, but a little lower: 0.02, $0.06,0.13,0.11$ and 0.46 , respectively. The mean and minimum values of transmissivity followed the same increasing order parallel with the defoliation process. The mean, median and mode values were always closer to the daily minimums than to the maximum values (Table 3, Figure 3).

An important shortcoming of the original measurement concept related to cloudy sky conditions can be noticed on the transmissivity curve of 9 / Sep / 2014 (Figure 2). Transmissivity increased sharply twice during the day, at 13:00 and 15:40, while the curve of $G_{\text {trans }}$ remained consistent. These apparent jumps in transmissivity did not mean a real increase in the solar permeability of A. hippocastanum. They can be explained with cumulus clouds above the reference station that caused immediate drops in the value of global radiation - however $G_{a c t}$ was measured more than $2 \mathrm{~km}$ away from the tree, which was thus unaffected by the clouds' shadow. If the reference $G_{a c t}$ value was measured on the top of an adjacent building, such sharp decreases of $G_{a c t}$ would be synchronous with the moderated decreases of $G_{\text {trans }}$ curve.

\section{Interspecies differences}

As the outlined problem of 'apparent transmissivity increase' has occurred many times on measurement days with variable sky conditions, it is advisable to compare the different species based on the data of clear days only. Another important criteria is to have as similar weather conditions as possible, namely to

Table 3. Basic descriptive statistics of Aesculus hippocastanum's transmissivity on different days

\begin{tabular}{|c|c|c|c|c|c|c|c|}
\hline Date & N & Mean & SD & Mode & Median & Min. & Max. \\
\hline 4 / Jul /2014 & 46 & 0.07 & 0.10 & 0.02 & 0.03 & 0.02 & 0.47 \\
\hline 24 / Jul / 2014 & 41 & 0.15 & 0.15 & 0.06 & 0.08 & 0.05 & 0.94 \\
\hline 9 / Sep / 2014 & 42 & 0.18 & 0.10 & 0.13 & 0.15 & 0.09 & 0.57 \\
\hline $30 /$ Sep / 2014 & 39 & 0.25 & 0.14 & 0.11 & 0.21 & 0.12 & 0.87 \\
\hline 28 / Oct / 2014 & 26 & 0.47 & 0.22 & 0.46 & 0.47 & 0.17 & 1.00 \\
\hline
\end{tabular}



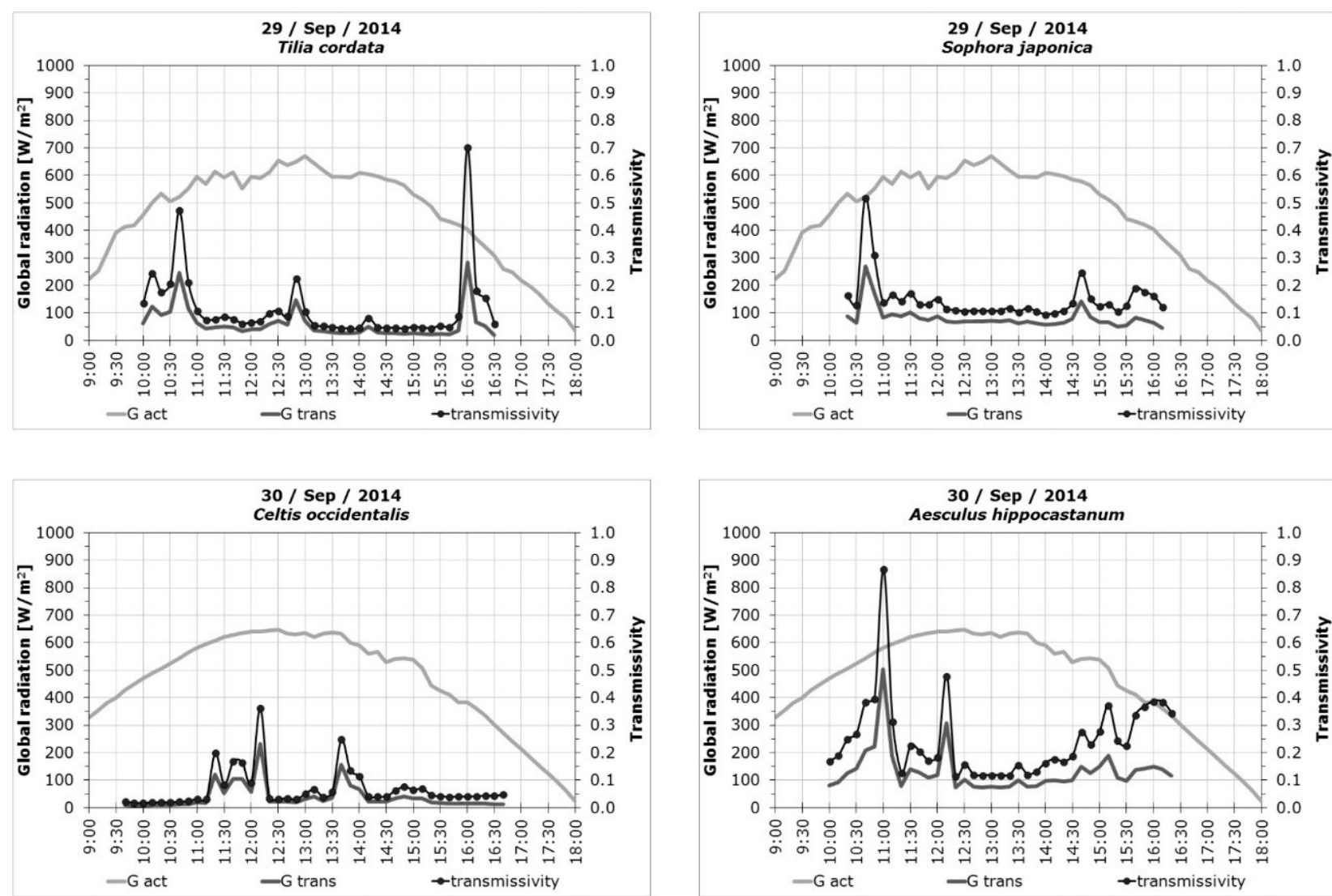

Figure 4. Transmissivity differences between the four trees on two consecutive clear days (time is in $C E T, G_{\text {act }}$ - actual value of global radiation, $G_{\text {trans }}$ - transmitted radiation)

investigate consecutive days when analyzing interspecies differences. From the 2014 database only the last days of September meet these demands (Table 2). Both days had nearly bell-shaped curves of global radiation $\left(G_{a c t}\right)$ with maximum values around $650 \mathrm{~W} /$ $\mathrm{m}^{2}$, but the $G_{\text {trans }}$-curves are obviously different indicating the differences between the tree canopies of the four species (Figure 4).

On 29 / Sep / 2014 S. japonica had clearly higher transmissivity than $T$. cordata: median values are 0.13 vs. 0.08 and the means are about 0.15 vs. 0.12 , respectively (Table 4, Figure 5). The differences on 30 / Sep / 2014 between the other tree-pair are even greater. $A$. hippocastanum's median transmissivity is 0.21 (mean: 0.25), while C. occidentalis can be characterized with the most effective shading: its median transmissivity is only 0.04 (mean: 0.07). The latter's shading potential is 5-times stronger in the end of September than that of $A$. hippocastanum. Not only the median, mean and mode values are higher in the case of $A$. hippocastanum's solar permeability, but it also has a more even distribution, and the values cover a wider range: $0.12-$ o.87. On the contrary, in the case of the other species the transmissivity values are clustered around a very specific mode: this is 0.04 for $C$. occidentalis and $T$. cordata, and 0.1 for S. japonica (Table 4, Figure 5).

Table 4. Basic descriptive statistics of the investigated species' transmissivity on the last two days of September 2014

\begin{tabular}{|l|c|c|c|c|c|c|c|}
\hline Species & N & Mean & SD & Mode & Median & Min. & Max. \\
\hline Celtis occidentalis & 43 & 0.07 & 0.07 & 0.04 & 0.04 & 0.02 & 0.36 \\
\hline Tilia cordata & 40 & 0.12 & 0.13 & 0.04 & 0.08 & 0.04 & 0.70 \\
\hline Sophora japonica & 36 & 0.15 & 0.08 & 0.10 & 0.13 & 0.09 & 0.52 \\
\hline Aesculus hippocastanum & 39 & 0.25 & 0.14 & 0.12 & 0.21 & 0.12 & 0.87 \\
\hline
\end{tabular}




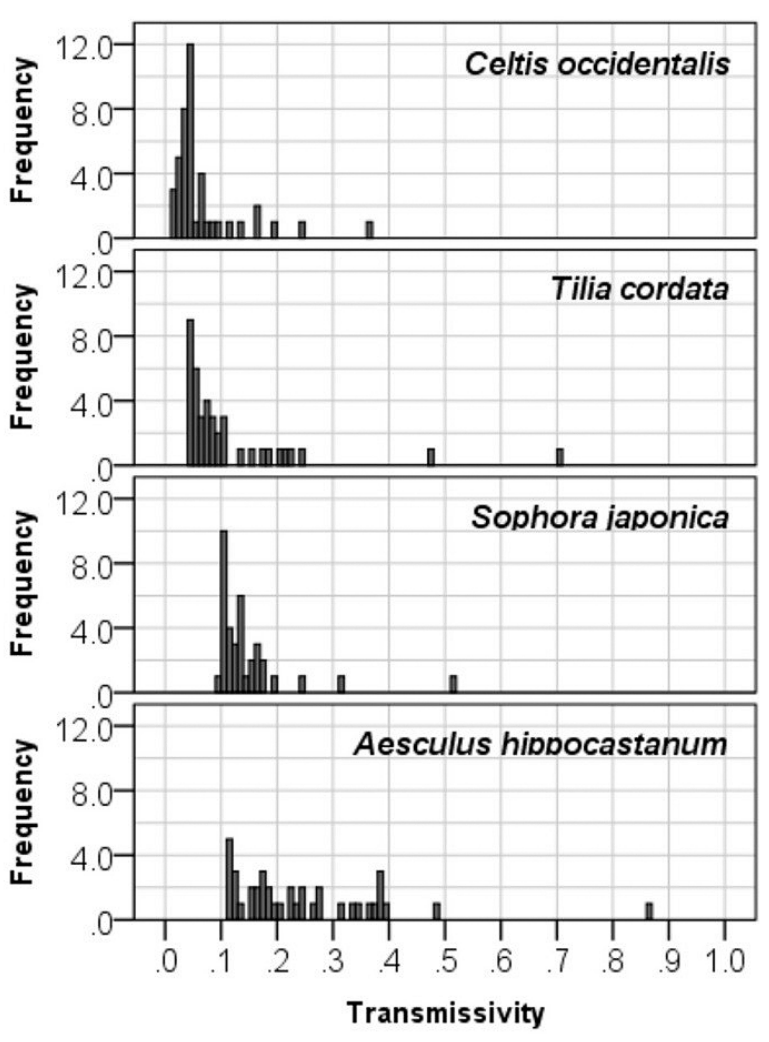

Figure 5. Transmissivity values of the different species on the last two days of September 2014

\section{Discussion}

\section{Discussion of the results}

The results from the end of September (Figures 4-5, Table 4) indicated higher shading capacity in the case of $T$. cordata and C. occidentalis, while S. japonica's sparser canopy could be characterized with higher transmissivity. The analysis clearly revealed a lower shading capacity in the case of A. hippocastanum, which is in line with our field observations, as this species starts autumn defoliation the earliest. Therefore the higher solar permeability of this tree can be explained with the half-leafless condition of the canopy at the end of September. T. cordata and C. occidentalis start to lose their leaves almost at the same time, after A. hippocastanum and before S. japonica. Nevertheless, compared only to T. cordata and C. occidentalis, $S$. japonica still had higher solar permeability in the end of September, thus the transmissivity in this case may depend more on the leaf area density (LAD) than on the amount of leaves on the tree. T. cordata and C. occidentalis have greater leaf surface and their foliage is denser than that of S. japonica's.

However it is worth noting that the foliation pattern during the spring follows a similar order: A. hippocastanum is the first to come into leaf and $S$. japonica the last. Therefore a longer and more thorough measurement campaign is planned including all relevant seasons of the foliation-defoliation process. In that way the results are expected to offer more detailed and reliable picture about the shading efficiency of common Hungarian park and street trees. Another good reason for prolonged research with many investigation days is that we found higher intra-annual changes in the case of the same tree (A. hippocastanum; Figures 2-3, Table 3) than the inter-species differences at the same time of the year (end of September; Figures 4-5, Table 4).

Seasonal comparison would be more creditable if the same A. hippocastanum specimen could be kept throughout the whole measurement period, because the dimensions of the studied trees (Table 1) may affect the $G_{\text {trans }}$ values. The greater tree crown volume in the first $A$. hippocastanum individual means a longer distance through the tree crown that the solar beam has to pass, enhancing the foliage absorption therefore lowering $G_{\text {trans. }}$. On the other hand, the greater trunk height in the second A. hippocastanum specimen means that larger amount of diffuse radiation may reach the sensor placed under the tree from lateral directions. Theoretically, both of these size-related differences allow measuring greater $G_{\text {trans }}$ under the second A. hippocastanum at the same time of the year, provided that both individuals are healthy.

Understanding the importance of the mentioned dimensional attributes and many other factors requires longer and deeper investigation. Namely, the microclimate regulation potential of trees depends not only on dimensional characteristics and age but other factors including leaf area, shape and structure of canopy, etc. Moreover, these factors vary if the trees' state of health deteriorates (Nowak, et al., 2008). The decline in health is more pronounced if the tree specimen does not tolerate harsh urban growing conditions or does not demonstrate resilience to other local conditions (Jim, 2012). Climate-conscious planning, preliminary site assessment and prudent selection of species (or cultivars) positively influence the health of the planted trees, and ensure that they can offer the full scale of their ecosystem services that the urban population expects from them. This study may be considered as the basic step offering direct data about the shading capacity, i.e. the micro-climate regulation services of different urban trees.

\section{Application of the results}

In order to facilitate urban landscape planning it would be important to use specific transmissivity values in numerical models that characterize appropriately the tree species planted frequently as street and park trees in a given geographical region. The outcomes of this study, as well as the results presented 
by earlier research (e.g. Shashua-Bar, et al., 2010; Konarska, et al., 2014), evince that canopy transmission shows huge differences reaching $4-30 \%$ in summer and $40-80 \%$ (deciduous trees) in winter. Although solar permeability depends on the leaf density, orientation of the leaves, and other tree crown-related characteristics influenced by the health conditions and the annual foliation cycle, microclimate simulation studies usually set a single default value to this attribute for all tree species. However, by the use of the SOLWEIG model (Lindberg, et al., 2008; Lindberg, Grimmond, 2011) it would be possible to alter this parameter (Konarska, et al., 2014).

The empirical transmissivity values of typical Hungarian tree species are planned to be integrated into radiation and micro-bioclimate modeling. In that way we can support the work of Hungarian landscape designers to simulate the bioclimatic effect of differently vegetated (planted with different species or cultivars in different extent) recreation areas, moreover to simulate the micro-bioclimatic effect of vegetation in the different seasons according to the foliation-defoliation process.

\section{Conclusion}

\section{Summary}

Human thermal comfort and the related thermal stress mitigation is one of the most intensively investigated issues of urban bioclimatology. The importance of this field is obvious when we consider the predicted trends of climate change and the increasing number of city-dwellers who would live under the even warmer climatic conditions of urbanized areas. Planting trees for their shading (shortwave radiation reduction) and evaporative cooling are axiomatic and simple 'means' in the hand of urban planners to mitigate thermal stress in the climate regions with long and warm summers. But there is still a great need for studies which offer quantitative data about the shading capacity as well as heat stress reduction potential of different types of trees. In order to help the work of urban planners and landscape designers, as well as to fill this research gap in Hungary, a long-term transmissivity-measurement campaign was started in the South-Hungarian city of Szeged. Tilia cordata, Sophora japonica, Celtis occidentalis and Aesculus hippocastanum were selected to investigate the interspecies differences and temporal changes in solar permeability, as these species occur frequently in urban parks, squares and streets in Central-European climate conditions.

The calculated transmissivity values varied greatly with the seasonal status of the canopy, and we found considerable inter-species differences too, evidencing that solar permeability depends on the amount of leaves, leaf density and other tree crown-related characteristics. Nevertheless, most microclimate simulation software set this attribute as default in the case of all trees. Our results therefore underline the importance of the usage of variable transmissivity values in numerical models in order to provide more reliable simulations. Such assessments can contribute to finding the most suitable tree species in urban landscape planning. Besides the micro-scale results, they can also contribute to the methodological development of local scale heat stress mapping, moreover to the indicator development for mapping climate regulation ecosystem services of urban green spaces.

\section{Future research plans}

Additional questions worth studying:

- How do the solar radiation reduction capacity of trees and their temporal and inter-species differences influence the bioclimatic conditions during the different seasons?

- What is the effect of crown-health conditions on the above-mentioned?

- Is it worth more to plant trees with smaller but denser foliage, or does a larger and sparser tree crown have more climatic benefits?

To meet the above-mentioned goals and to overcome the problem of 'apparent transmissivity increase' caused by the variable sky conditions and the too distant reference station, a new research design was introduced from the spring of 2015. Reference global radiation $\left(G_{a c t}\right)$ data are no more recorded using the pyranometer on the top of the university building (inner-city weather station). Instead, one of the mobile stations is placed at an open point nearby the investigated trees. This arrangement ensures that both $G_{a c t}$ and $G_{\text {trans }}$ are influenced by the very same sky conditions (sunny-cloudy periods); moreover, the temporal resolution of the data is refined to 1-minute. A further benefit of the new measurement design is the potential for complex microclimate analyses, as short- and longwave components of the radiation budget, air temperature, humidity and wind velocity are measured not only under the tree crown but also at an open and sunny point of the same study area. Besides the micro-bioclimate regulating potential of the four tree species, the seasonal status of the canopy is also recorded via photos and fish-eye photos. To study the effect of foliagehealth conditions on transmissivity values, from 2015 both the healthy A. hippocastanum and the leaf miner-attacked individuals are included into the investigation-series. They are monitored on consecutive days with almost the same weather conditions. 
The measurement-based transmissivity values of different tree species can serve as input for radiationand bioclimate modeling software to support more reliable simulations. In the near future we plan numerical simulations to investigate the effect of tree species selection (meaning transmissivity and shadowed area differences) on the resulting reduction of radiation load. SOLWEIG software is planned to become the basic tool for modeling the spatial distribution of mean radiant temperature in different urban structures (e.g. squares and streets with different orientation) planted with different types of trees. Instead of preset transmissivity values, this software allows replacing them with real, measurement based transmissivity that characterizes properly the shading efficiency of Hungarian street and park trees. Because of the significant annual change in transmissivity values (we found greater seasonal changes than inter-species differences at the same time of the year) we plan to incorporate these annual differences in the modeling procedure too.

Contribution to the knowledge about the thermal stress mitigation effect of different local tree species in urban areas will help landscape planners to design 'successful' outdoor spaces which may be perceived more comfortable by people and used more frequently by the citizens.

\section{Acknowledgements}

This research was carried out in the frames of TÁMOP 4.2.4. a/2-11-1-2012-0oo1 „National Excellence Program - Elaborating and operating an inland student and researcher personal support system". The project was subsidized by the european union and co-financed by the european social fund. Authors wish to thank the colleagues who helped with their advice during the investigations. We are also grateful for the positive critics from peer-scientists who commented our researches on the $9^{\text {th }}$ International Conference on Urban Climate (ICUC9) held in Toulouse, France (July 20-24, 2015).

\section{References}

Akbari, H., Bretz, S., Kurn, D., Hanford, J. 1997. Peak Power and Cooling Energy Savings of High-Albedo Roofs. Energy and Buildings 25, 117-126.

Berry, R., Livesley, S.J., Ayeb, L. 2013. Tree canopy shade impacts on solar irradiance received by building walls and their surface temperature. Builing and Environment 69, 91-100.

Bowler, D.E., Buyung-Ali, L., Knight, T.M., Pullin, A.S. 2010. Urban greening to cool towns and cities: a systematic review of the empirical evidence. Landscape and Urban Planning 97, 147-155.
Cantón, M.A., Cortegoso, J.L., Derosa, C. 1994. Solar permeability of urban trees in cities of western Argentina. Energy and Buildings 20, 219-230.

Carver, A.D., Unger, D.R., Parks, C.L. 2004. Modeling Energy Savings from Urban Shade Trees: An Assessment of the CITYgreen ${ }^{\circledast}$ Energy Conservation Module. Environmental Management 34, 650-655.

Donovan, G.H., Butry, D.T. 2009. The value of shade: Estimating the effect of urban trees on summertime electricity use. - Energy and Buildings 41, 662668.

Erell, E., Pearlmutter, D., Williamson, T. 2011. Urban microclimate: Designing the spaces between buildings. Earthscan, London, 266 pp.

Égerházi, L.A., Kántor, N., Gál, T. 2013. Evaluation and modelling the micro-bioclimatological conditions of a popular playground in Szeged, Hungary. International Review of Applied Sciences and Engineering 4, 57-61.

Égerházi, L.A., Kovács, A., Takács, Á., Égerházi, L. 2014. Comparison of the results of two micrometeorological models and measurements. Acta Climatologica et Chorologica Universitatis Szegediensis $47-48,33-42$.

Gulyás, Á., Unger, J. 2010. Analysis of bioclimatic loads inside and outside the city in a long-term and an extremely hot short-term period (Szeged, Hungary). Urban Climate News 37, 11-14.

IPCC 2014. Climate Change 2014: Synthesis Report. Contribution of Working Groups I, II and III to the Fifth Assessment Report of the Intergovernmental Panel on Climate Change [Core Writing Team, Pachauri, R.K., Meyer, L.A. (eds.)]. IPCC, Geneva, $151 \mathrm{pp}$.

Jim, Y. 2012. Roadside trees in urban Hong Kong: Part IV: Tree growth and enviromental condition. Journal of Arboriculture 21, 89-99.

Kántor, N., Unger, J. 2011. The most problematic variable in the course of human-biometeorological comfort assessment - The mean radiant temperature. Central European Journal of Geosciences 3, 90-100.

Kántor, N., Kovács, A., Takács, Á. 2016: Small-scale human-biometeorological impacts of shading by a large tree. Open Geosciences Ms. No. OPENGEOD-15-00131R1.

Konarska, J., Lindberg, F., Larsson, A., Thorsson, S., Holmer, B. 2014. Transmissivity of solar radiation through crowns of single urban trees - application for outdoor thermal comfort modelling. Theoretical and Applied Climatology 117, 363-376.

Lee, H., Holst, J., Mayer, H. 2013. Modification of human-biometeorologically significant radiant flux densities by shading as local method to mitigate heat stress in summer within urban street canyons. Advances in Meteorology 2013, Article ID 312572. 
Lee, H., Mayer, H., Schindler, D. 2014. Importance of 3-D radiant flux densities for outdoor human thermal comfort on clear-sky summer days in Freiburg, Southwest Germany. Meteorologische Zeitschrift 23, 315-330.

Lindberg, F., Grimmond, CS.B. 2011. The influence of vegetation and building morphology on shadow patterns and mean radiant temperatures in urban areas: model development and evaluation. Theoretical and Applied Climatology 105, 311-323.

Lindberg, F., Holmer, B., Thorsson, S. 2008. SOLWEIG 1.0 - modelling spatial variations of $3 \mathrm{D}$ radiant fluxes and mean radiant temperature in complex urban settings. International Journal of Biometeorology 52, 697-713.

Mayer, H. 2008. KLIMES - a joint research project on human thermal comfort in cities. Ber. Meteor. Inst. Albert-Ludwigs Univ. Freiburg 17, 101-117.

Mayer, H., Holst, J., Dostal, P., Imbery, F., Schindler, D. 2008. Human thermal comfort in summer within an urban street canyon in Central Europe. Meteorologische Zeitschrift 17, 241-250.

Nakaohkubo, K., Hoyano, A. 2011. Development of passive designe tool using $3 \mathrm{D}$-Cad compatible thermal simulation - prediction of indoor radiation environment considering solar shaving by surrounding trees and buildings. In: Proc. of Building Simulation 2011, Sydney, 2711-2717.

Nowak, D.J., Crane, D.E., Stevens, J.C., Hoehn, R.E., Walton, J.T., Bond, J. 2008. A Ground-Based Method of Assessing Urban Forest Structure and Ecosystem Services. Arboriculture \& Urban Forestry 34, 347-358.

Potchter, O., Ben-Shalom, H.I.2013. Urban warming and global warming: Combined effect on thermal discomfort in the desert city of Beer Sheva, Israel. Journal of Arid Environments 11, 113-122.
Shahidan, M.F., Shariff, M.K. M., Jones, P., Salleh, E., Abdullah, A.M. 2010. A comparison of Mesua ferrea L. and Hura crepitans L. for shade creation and radiation modification in improving thermal comfort. Landscape and Urban Planning 97, 168-181.

Shashua-Bar, L., Hoffman, M.E. 200o. Vegetation as a climatic component in the design of an urban street - an empirical model for predicting the cooling effect of urban green areas with trees. Energy and Buildings 31, 221-235.

Shashua-Bar, L., Tsiros, I. X., Hoffman, M. E. 2010. A modeling study for evaluating passive cooling scenarios in urban streets with trees. Case study: Athens, Greece. Building and Environment 45, 2798-2807.

Shashua-Bar, L., Pearlmutter, D., Erell, E. 2011. The influence of trees and grass on outdoor thermal comfort in a hot-arid environment. International Journal of Climatology 31, 1498-1506.

Shashua-Bar, L., Potchter, O., Bitan, A., Boltansky, D., Yaakov, Y. 2009. Microclimate modelling of street tree species effects within the varied urban morphology in the Mediterranean city of Tel Aviv, Israel. International Journal of Climatology 30, 44-57.

UNFPA 2011. The State of World Population 2011. Report of the United Nations Population Fund. UNFPA, New York, 132 pp.

WMO 1996. Climatological Normals (CLINO) for the period 1961-1990. WMO/OMM-No 847. Secretariat of the World Meteorological Organization, Geneva, $768 \mathrm{pp}$.

Zuvela-Aloise, M., Bokwa, A., Dobrovolny, P., Gál, T., Geletic, J., Gulyás, Á., Hajto, M., Hollosi, B., Kielar, R., Lehnert, M., Skarbit, N., Stastny, P., Svec, M., Unger, J., Vysoudil, M., Walawender, J.P. 2015. Modelling urban climate under global climate change in Central European cities. In: Geophysical Research Abstracts, Paper EGU 2015-1594. 